\title{
Beggar-Thy-Neighbor Advertising: Theory and Application to Generic Commodity Promotion Programs
}

\author{
Julian M. Alston, John W. Freebairn, And Jennifer S. James
}

\begin{abstract}
Profits from generic advertising by a producer group often come partly at the expense of producers of closely related commodities. The resulting tendency toward excessive advertising is exacerbated by check-off funding. To analyze this beggar-thy-neighbor behavior we compare a scenario where different producer groups cooperate and choose their advertising expenditures jointly to maximize the sum of profits across the groups, and a scenario where they optimize independently. In an illustrative example using 1998 data for U.S. beef and pork, the noncooperatively chosen expenditure on beef and pork advertising is more than three times the cooperative optimum
\end{abstract}

Key words: cooperative and noncooperative solutions, excessive advertising, mandated commodity promotion programs, U.S. beef and pork.

In the United States, generic commodity promotion programs spend around $\$ 1$ billion per year on domestic and export promotion, funded mostly by commodity taxes, commonly referred to as check-offs (Vande Kamp and Kaiser provide details). In recent years, there have been numerous court cases and other contention over whether such mandatory programs should be continued. These disputes were driven by intraindustry effects: the total benefits and costs and the distribution of costs and benefits among producers and handlers of a given commodity covered by a promotion program.

A potentially important issue that was not addressed in the disputes is the effect of such programs on producers of related commodities, and on consumers. When the promotion of a particular product successfully increases the demand for that product, the demands for related commodities are

\footnotetext{
Julian M. Alston is a professor in the Department of Agricultural and Resource Economics, University of California, Davis, and a member of the Giannini Foundation of Agricultural Economics. John W. Freebairn is a professor and Head of the Department of Economics, University of Melbourne. Jennifer S. James is an assistant professor in the Department of Agricultural Economics and Rural Sociology, Pennsylvania State University. Senior authorship is not assigned.

The authors gratefully acknowledge helpful comments from Richard Sexton, Robert Myers, Harry Kaiser, and an anonymous reviewer, as well as workshop participants at the University of Melbourne and the University of Minnesota. Partial funding support for this work was provided by the Giannini Foundation of Agricultural Economics and the National Institute for Commodity Promotion Research and Evaluation.
}

likely to shift as well. ${ }^{1}$ These cross-product effects may occur as a result of price changes induced by the demand increasing effect of the advertising and by the cost increasing effect of the levy to fund it, or because advertising of one commodity directly reduces the demand for another commodity. For instance, when beef promotion leads to an increase in demand and a rise in the price of beef, there will be induced increases in the demands for substitutes such as pork and chicken, even if the advertising does not affect pork and chicken demands directly. In addition, however, beef promotion may also cause a reduction in demand for pork and poultry. Hence, beef advertising may induce changes in the demands and thus changes in the prices of all three goods, which feed back into the demands, causing a further round of demand shifts and price changes. Producer groups need to consider such cross-commodity feedback effects in

\footnotetext{
'Examples where generic commodity programs funded by check-offs may have important cross-commodity impacts include the programs for individual meats (such as beef and pork), butter and margarine, individual nuts (such as almonds, walnuts, and pistachios), individual dried fruits (such as prunes, apricots, and raisins), and individual fresh fruits or groups of fresh fruits (such as avocados, table grapes, citrus, and the stone fruits covered by the "tree fruit agreement," namely peaches, pears, nectarines, and plums). Forker and Ward, Lee et al., and Vande Kamp and Kaiser document many of these programs.
} 
determining their own investments in product promotion. ${ }^{2}$ The cross-commodity effects also have implications for social welfare and for appropriate policy. ${ }^{3}$ In the most likely case, benefits to beef producers come partly at the expense of producers of pork or chicken, but the costs to pork and chicken producers will be (rationally) ignored by beef producers in deciding how much to spend on promotion.

In this article, we focus on this beggar-thyneighbor element, which is implicit when a substantial part of the benefits to the producers authorizing the program come at the expense of producers of competing commodities. Such cross-commodity effects have been noted in previous studies since the earliest work on commodity advertising (e.g., Hoos; Parish; De Boer; Piggott et al. 1996), but until recently have not been analyzed. Several recent studies have drawn attention to the beggar-thy-neighbor aspect of commodity promotion programs, and its potential importance, but they all treated the advertising expenditure and levy as exogenous (e.g., Piggott, Piggott, and Wright; Piggott 1997; Alston, Chalfant, and Piggott 2000; and Kinnucan and Miao). Here, we go a step further and treat the advertising expenditure as a choice variable.

Optimal advertising strategies are analyzed under scenarios where producer groups act noncooperatively or cooperatively in choosing their advertising budgets. We allow for own- and cross-commodity impacts of generic commodity promotion programs in terms of their effects on profits of producers of the advertised commodity (and thus the optimal promotion budget), and on profits of producers of substitute commodities. ${ }^{4}$ Throughout, we assume competitive industries, with prices determined by the intersection of supply and demand, and collective action by producer groups to undertake advertising. Initially, a

\footnotetext{
${ }^{2}$ Intuitively, to account for such cross-commodity price feedback effects amounts essentially to using a Buse-type "total" own-price elasticity of demand rather than a conventional "partial" elasticity in the optimal advertising rule from a single-market model. Such elasticities are discussed by Piggott (1992).

${ }^{3}$ Other than noting the effects on consumer prices and quantities, no assessment of the consumer welfare effects of advertising is considered in this article. Exactly how to measure the consumer welfare effects of advertising is not fully resolved $1 \rightarrow$ Becker and Murphy for a general discussion and Alston, Chalfant, and Piggott 1998 for some more-specifically relevant discussion and empirical work).

${ }^{4}$ Throughout the atricle we use the terms "optimal" advertising expenditure or "optimal" advertising intensity as shorthand for the expenditure or intensity that maximizes producer surplus or the return to quasi-fixed factors.
}

multimarket equilibrium model is used to derive qualitative results. Then, using data and elasticity estimates for the U.S. meat market, we illustrate the importance of the beggar-thy-neighbor element in the case of generic advertising of beef by the Beef Industry Council and pork by the National Pork Producers Council.

\section{Optimal Advertising}

We begin with a model of $n$ goods related in demand but not supply. The quantities and prices of all of the goods $\left(Q_{i}, P_{i}\right.$, for $i=1$ to $n$ ) are jointly endogenous and determined competitively, given the generic advertising expenditures $\left(A_{i}\right)$ chosen by each of $m$ producer groups $(m \leq n)$. The equations for demand and supply, for $i=1, \ldots, n$, are ${ }^{5}$

$$
\begin{aligned}
& \text { (1) } Q_{i}=\mathrm{d}_{i}\left(P_{1}, P_{2}, \ldots, P_{n}, A_{1}, A_{2}, \ldots, A_{m}\right) \\
& \text { (2) } Q_{i}=\mathrm{s}_{i}\left(P_{i}^{P}\right)
\end{aligned}
$$

where $P_{i}^{P}$ is the producer price, which may differ from the buyer price $P_{i}$ depending on the method used to fund the advertising. Under lump-sum funding, $P_{i}^{P}=P_{i}$ and $A_{i}$ does not depend directly on price or quantity. Under ad valorem check-off funding, $P_{i}^{P}=$ $\left(1-t_{i}\right) P_{i}$ and $A_{i}=t_{i} P_{i} Q_{i}$. Under per unit check-off funding, $P_{i}^{P}=P_{i}-T_{i}$ and $A_{i}=$ $T_{i} Q_{i}$.

\section{Noncooperative Advertising with Lump-Sum Funding}

Initially, we assume the advertising is funded in a lump-sum fashion. For each group of producers, $i$, profits, $\pi_{i}$, are equal to total revenue, $P_{i} \mathrm{~d}_{i}(\cdot)$, minus total variable cost of production, $T V C_{i}\left(Q_{i}(\cdot)\right)$ and the cost of advertising, $A_{i}$, so that ${ }^{6}$

$$
\begin{aligned}
\pi_{i}= & P_{i} \mathrm{~d}_{i}\left(P_{1}, P_{2}, \ldots, P_{n}, A_{1},\right. \\
& \left.A_{2}, \ldots, A_{m}\right)-T V C_{i}\left(Q_{i}(\cdot)\right)-A_{i} .
\end{aligned}
$$

Suppose group $i$ chooses $A_{i}$ to maximize its profit, as defined in equation (3), treating the

\footnotetext{
${ }^{5}$ For simplicity, we refer to demand in (1) as farm-level demand. Strictly, advertising is at the retail level, and a marketing margin separates retail and farm levels. With additional complexity, the model could be extended to include a marketing sector as illustrated, for example, by Kinnucan (1997). The analysis could also be extended readily to allow for interdependencies in production.

${ }^{6}$ Under the assumption of a competitive industry, the supply function in equation (2) is the marginal cost from the total variable cost of production, $T V C_{i}\left(Q_{i}(\cdot)\right)$, used in defining producer profit in equation (3).
} 
advertising expenditures by all other groups as given. Then the first-order necessary condition for a maximum is

$$
Q_{i} \frac{\partial P_{i}}{\partial A_{i}}=1
$$

where price has been set equal to marginal cost (i.e., $P_{i}=\partial T V C_{i} / \partial Q_{i}$ ), as an implication of competition. ${ }^{7}$ Equation (4) can be written equivalently as

$$
\frac{d \ln P_{i}}{d \ln A_{i}}=\frac{A_{i}}{P_{i} Q_{i}} .
$$

To solve for the profit-maximizing value for $A_{i}$ in equation (5), first we differentiate the equilibrium conditions for the $n$ markets, taking into account that the price of each good may change as a result of the advertising choice made by the group of interest. The equilibrium condition in the $i$ th market is defined by

$$
\text { (6) } \mathrm{s}_{i}\left(P_{i}\right)=\mathrm{d}_{i}\left(P_{1}, P_{2}, \ldots, P_{n}, A_{1}, A_{2}, \ldots A_{m}\right) \text {. }
$$

Totally differentiating the $n$ market equilibrium conditions and converting into elasticity terms, we get

$$
\begin{aligned}
& \left(\left[\begin{array}{cccc}
\epsilon_{1} & 0 & \cdots & 0 \\
0 & \epsilon_{2} & & 0 \\
\vdots & & \ddots & \vdots \\
0 & 0 & \cdots & \epsilon_{n}
\end{array}\right]-\left[\begin{array}{cccc}
\eta_{11} & \eta_{12} & \cdots & \eta_{1 n} \\
\eta_{21} & \eta_{22} & \cdots & \eta_{2 n} \\
\vdots & \vdots & \ddots & \vdots \\
\eta_{n 1} & \eta_{n 2} & \cdots & \eta_{n n}
\end{array}\right]\right) \\
& \times\left[\begin{array}{c}
d \ln P_{1} \\
d \ln P_{2} \\
\vdots \\
d \ln P_{n}
\end{array}\right]=\left[\begin{array}{cccc}
\alpha_{11} & \alpha_{12} & \cdots & \alpha_{1 m} \\
\alpha_{21} & \alpha_{22} & \cdots & \alpha_{2 m} \\
\vdots & \vdots & \ddots & \vdots \\
\alpha_{n 1} & \alpha_{n 2} & \cdots & \alpha_{n m}
\end{array}\right] \\
& \times\left[\begin{array}{c}
d \ln A_{1} \\
d \ln A_{2} \\
\vdots \\
d \ln A_{m}
\end{array}\right]
\end{aligned}
$$

or, more compactly,

$$
(\mathbf{E}-\mathbf{H}) \hat{\mathbf{p}}=\Omega \hat{\mathbf{a}}
$$

where $\mathbf{E}$ is a diagonal matrix of supply elasticities [the typical element $\epsilon_{i}=$ $\left(\partial \mathrm{s}_{i}(\cdot) / \partial P_{i}\right)\left(P_{i} / Q_{i}\right)>0$ is the elasticity of

\footnotetext{
${ }^{7}$ For completeness, we also assume there are non-negative profits from advertising, that in the vicinity of the solution to the maximum we have diminishing returns to advertising (i.e., $\left.\partial^{2} Q_{i} / \partial A_{i}^{2} \leq 0\right)$, and that the demand and supply equations have the usual regularity properties.
}

supply of good $i]$. $\mathbf{H}$ is an $n \times n$ matrix of elasticities of demand with respect to prices [the typical element $\eta_{i j}=\left(\partial d_{i}(\cdot) / \partial P_{j}\right)\left(P_{j} / Q_{i}\right)$ is the elasticity of demand for good $i$ with respect to the price of good $j], \Omega$ is an $n \times m$ matrix of elasticities of demand with respect to advertising [the typical element $\alpha_{i j}=\left(\partial \mathrm{d}_{i}(\cdot) / \partial A_{j}\right)\left(A_{j} / Q_{i}\right)$ is the elasticity of demand for good $i$ with respect to advertising of good $j$ ], $\hat{\mathbf{p}}$ is an $n$-vector of proportional changes in prices (i.e., $d \ln P_{i}$ ), and $\hat{\mathbf{a}}$ is an $m$-vector of proportional changes in advertising expenditures (i.e., $\left.d \ln A_{i}\right){ }^{8}$

Premultiplying both sides of equation (7) by $(\mathbf{E}-\mathbf{H})^{-1}$ yields the vector of proportional changes in prices as a function of the proportional changes in advertising expenditures

$$
\hat{\mathbf{p}}=(\mathbf{E}-\mathbf{H})^{-1} \Omega \hat{\mathbf{a}}=\mathbf{L} \hat{\mathbf{a}}
$$

where

$$
\mathbf{L}=(\mathbf{E}-\mathbf{H})^{-1} \Omega .
$$

Then, using the assumption that $d \ln A_{i} / d \ln A_{j}=0$, the elements of $\mathbf{L}$ represent the own- and cross-commodity elasticities of prices with respect to advertising: $d \ln P_{i} / d \ln A_{j}=L_{i j}$. The diagonal elements represent the own-price effects of advertising, given fixed advertising by other groups: $d \ln P_{i} / d \ln A_{i}=L_{i i}$. Setting this term for each of the $m$ groups equal to its advertising intensity, as given by the first-order conditions, equation (5), and transforming yields a set of $m$ simultaneous equations that implicitly define the $m$ advertising expenditures:

$$
A_{i}^{N}=P_{i} Q_{i} L_{i i} \text {. }
$$

The solution to this system of equations defines the noncooperative equilibrium in terms of the supply and demand parameters.

\section{Cooperative Advertising with Lump-Sum Funding}

In contrast to the optimization problem presented above, suppose producer groups

\footnotetext{
${ }^{8}$ Economic theory implies restrictions on these matrices of elasticities. Symmetry and homogeneity restrictions apply to the matrix of demand elasticities, $\mathbf{H}$. Further, if the model covers the expenditure on all of the goods in the relevant group (either all of current-period consumption expenditure, or expenditure on all of the goods in a separable group) the budget constraint implies a restriction that the share-weighted sum of advertising elasticities across the goods in the group is equal to zero-i.e., advertising causes a reallocation of a given total budget $(M)$ but cannot change the total bud $\rightarrow$ (Basmann). That is, $\mathbf{w}^{\prime} \Omega=\mathbf{0}$, where $\mathbf{w}$ is an $n$-vector of budget shares with typical element $w_{i}=P_{i} Q_{i} / M$.
} 
cooperate and choose the advertising expenditures $A_{1}$ through $A_{m}$ jointly in order to maximize the sum of their profits:

$$
\begin{aligned}
\pi=\sum_{i=1}^{m} \pi_{i} \\
=\sum_{i=1}^{m}\left[P_{i} \mathrm{~d}_{i}\left(P_{1}, \ldots, P_{n}, A_{1}, \ldots, A_{m}\right)\right. \\
\left.\quad-T V C_{i}\left(Q_{i}(\cdot)\right)-A_{i}\right]
\end{aligned}
$$

Taking the derivatives of the profit function with respect to $A_{1}$ through $A_{m}$ and setting those derivatives equal to zero, we get $m$ firstorder conditions, for $i=1$ to $m$,

$$
\sum_{j=1}^{m} Q_{j} \frac{\partial P_{j}}{\partial A_{i}}=1
$$

which can be written equivalently as

$$
A_{i}=\sum_{j=1}^{m} P_{j} Q_{j} \frac{d \ln P_{j}}{d \ln A_{i}}
$$

Hence, the solutions for the cooperative advertising budgets are implicitly defined using the $d \ln P_{i} / d \ln A_{j}=L_{i j}$ terms from equation (9), as the solution to the $m$ simultaneous equations, for $i=1$ to $m$ :

$$
A_{i}^{C}=\sum_{j=1}^{m} P_{j} Q_{j} L_{j i}
$$

The noncooperative solution, defined by equation (10), can be seen as a special case of the cooperative solution, defined by equation (14), which holds when all of the cross-price effects of advertising are zero (i.e., $d \ln P_{i} / d \ln A_{j}=L_{i j}=0$ for $\left.i \neq j\right)$. When these terms are not zero, the cooperative and noncooperative solutions will be different. In either case, the right-hand sides of equations (10) and (14) include revenue terms $\left(P_{i} Q_{i}\right)$ that are functions of the entire vector of advertising expenditures. In order to determine explicit solutions for $A_{1}$ through $A_{m}$, under either cooperative or noncooperative arrangements for lump-sum funded generic advertising, specific demand functions must be specified, and the revenue terms must be substituted out of the expressions to obtain solutions for $A_{1}$ through $A_{m}$ as functions of the parameters of the model.

\section{Advertising Funded by Per Unit and Ad Valorem Check-Offs}

When commodity advertising is funded through a per unit check-off, $T_{i}$, total advertising on the commodity is $A_{i}=T_{i} Q_{i}$, and the quantity of that check-off is chosen in order to maximize profits, where profit for group $i$ is defined as

$$
\begin{aligned}
\pi_{i}= & \left(P_{i}-T_{i}\right) \mathrm{d}_{i}\left(P_{1}, \ldots, P_{n}, A_{1}, \ldots, A_{m}\right) \\
& -T V C_{i}\left(Q_{i}(\cdot)\right) .
\end{aligned}
$$

Taking the derivative of group $i$ 's profit function with respect to $T_{i}$ and setting it equal to zero, we get the first-order condition

(16) $\frac{\partial P_{i}}{\partial T_{i}}=1$

which can be written equivalently as

$$
\frac{d \ln P_{i}}{d \ln T_{i}}=\frac{T_{i}}{P_{i}}
$$

The value of the first-order condition in equation (17) is determined by totally differentiating the market equilibrium conditions and solving for $d \ln P_{i} / d \ln T_{i}$. Along with identities equating supply and demand, the equilibrium conditions now include identities relating total advertising expenditure by each group to the check-off chosen:

$$
\begin{gathered}
\mathrm{s}_{i}\left(P_{i}-T_{i}\right)=\mathrm{d}_{i}\left(P_{1}, \ldots, P_{n},\right. \\
\left.A_{1}, \ldots, A_{m}\right) \\
A_{i}=T_{i} Q_{i} .
\end{gathered}
$$

For the case where advertising is funded using a check-off specified on an ad valorem basis, the solution is found similarly, but with $\mathrm{s}_{i}\left(\left(1-t_{i}\right) P_{i}\right)$ and $A_{i}=t_{i} P_{i} Q_{i}$.

The type of funding mechanism plays an important role in determining the optimal advertising expenditure. In a single-market model, when the advertising is funded by a check-off rather than lump sum, some of the cost of advertising is borne by consumers; with lump-sum funding, the final incidence is entirely on producers. Consequently, ceteris paribus a producer group's optimal advertising expenditure will tend to be greater under check-off funding. ${ }^{9}$ This

\footnotetext{
${ }^{9}$ This relationship between optimal advertising expenditure rules for producer groups under check-offs versus lump-sum funding in the single-market case was demonstrated by Alston, Carman, and Chalfant.
} 
holds for both per unit and proportional (ad valorem) check-offs. In a multimarket setting, the funding mechanism for advertising has further implications, because collection of the check-off has cross-commodity price implications-another form of shifting incidence-as well as distributional implications between producers and consumers of the commodity being taxed.

\section{A Two-Market Example}

In order to demonstrate the nature of the market interactions more clearly with explicit solutions, in this section we use a model of the interaction between two producer groups (i.e., for $m=n=2$ ). To derive concrete results, we impose additional assumptions about elasticities and functional forms. We assume that the two goods are gross substitutes in consumption (i.e., $\partial Q_{i} / \partial P_{j}>0$ ), the own-commodity effect of advertising on demand is positive (i.e., $\partial Q_{i} / \partial A_{i}>0$ ), and the cross-commodity effect of advertising on demand is negative (i.e., $\partial Q_{i} / \partial A_{j}<0$ ). The own-commodity effect must give rise to an increase in the own-commodity price (i.e., $\left.\partial P_{i} / \partial A_{i}>0\right)$, if it is to be profitable for the producer group paying for the advertising. Even with these restrictive assumptions, advertising by each group of producers may be inimical or favorable to the interests of the other group, depending on whether the (negative) direct cross-commodity effect of advertising exceeds the (positive) indirect cross-commodity price effect, which comes from the advertising-induced increase in the price of the advertised good.

\section{Noncooperative Advertising with Lump-Sum Funding}

In modeling the noncooperative case for two goods, we interpret the solutions in equation (10) as a pair of reaction functions, which express each group's optimal advertising expenditure as a function of the other group's advertising expenditure: $A_{1}^{*}=$ $R_{1}\left(A_{2}\right)$ and $A_{2}^{*}=R_{2}\left(A_{1}\right)$. Our focus is on the case where these reaction functions are negatively sloped, $\partial A_{1}^{*} / \partial A_{2}<0$ and $\partial A_{2}^{*} / \partial A_{1}<0$. Then, the equilibrium is defined by the intersection of the two reaction functions. In the case of two goods, we can write equation (10) as

(20)

$$
\begin{aligned}
& A_{1}=P_{1} Q_{1}(\cdot)\left[\frac{\alpha_{11}\left(\epsilon_{2}-\eta_{22}\right)+\alpha_{21} \eta_{12}}{D}\right] \\
& A_{2}=P_{2} Q_{2}(\cdot)\left[\frac{\alpha_{22}\left(\epsilon_{1}-\eta_{11}\right)+\alpha_{12} \eta_{21}}{D}\right]
\end{aligned}
$$

where $D=\left(\epsilon_{1}-\eta_{11}\right)\left(\epsilon_{2}-\eta_{22}\right)-\eta_{12} \eta_{21}$, and $D>0$ is implied by regularity conditions (a sufficient condition is that both goods are normal, with positive income elasticities, and positive supply elasticities; see Kinnucan 1996). Because group 1 takes into account that $Q_{1}$ in equation (20) depends on both $A_{1}$ and $A_{2}$, the optimal solution for $A_{1}$ depends on $A_{2}$ (and conversely for group 2 ). ${ }^{10}$

Because the $Q_{i}$ terms on the RHS of equations (20) and (21) are functions of $A_{1}$ and $A_{2}$, functional forms for the demand equations must be specified in order to derive explicit solutions for the two reaction functions. We consider the case of constant elasticity demand and supply functions, where the market relationships are defined by

$$
\begin{aligned}
& Q_{i}^{D}=\beta_{i} P_{1}^{\eta_{i 1}} P_{2}^{\eta_{i 2}} A_{1}^{\alpha_{i 1}} A_{2}^{\alpha_{i 2}} \\
& Q_{i}^{S}=\gamma_{i} P_{i}^{\epsilon_{i}} .
\end{aligned}
$$

By substituting the demand functions into equations (20) and (21), and using the equilibrium conditions to eliminate prices from these expressions, we obtained an expression for optimal advertising by group 1 as a function of advertising by group 2 and parameters of the model-the reaction function for group 1,

$$
A_{1}^{*}=K_{1} A_{2}^{\left(1+\epsilon_{1}\right)\left[\alpha_{12}\left(\epsilon_{2}-\eta_{22}\right)+\alpha_{22} \eta_{12}\right] /(D-F)}
$$

where $F=\left(1+\epsilon_{1}\right)\left[\alpha_{21} \eta_{12}+\alpha_{11}\left(\epsilon_{2}-\eta_{22}\right)\right]$, and $K_{1}$ is a positive constant, defined by

$$
\begin{aligned}
K_{1}= & {\left[\beta_{1} \frac{\alpha_{11}\left(\epsilon_{2}-\eta_{22}\right)+\alpha_{21} \eta_{12}}{D}\right]^{D /(D-F)} } \\
& \times\left[\frac{\beta_{1}}{\gamma_{1}}\right]^{\left(\left(1+\eta_{11}\right)\left(\epsilon_{2}-\eta_{22}\right)+\eta_{12} \eta_{21}\right) /(D-F)} \\
& \times\left[\frac{\beta_{2}}{\gamma_{2}}\right]^{\eta_{12}\left(1+\epsilon_{1}\right) /(D-F)}
\end{aligned}
$$

\footnotetext{
${ }^{10}$ Note that, if all of the cross-elasticities were zero, equations (20) and (21) would reduce to the equivalent of the Nerlove and Waugh result: $A_{i} / P_{i} Q_{i}=\alpha_{i i} /\left(\epsilon_{i}-\eta_{i i}\right)$. Assuming a fixed supply $\left(\epsilon_{i}=0\right)$, these conditions would reduce further to the Dorfman and Steiner result for optimal advertising by a monopoly: $A_{i} / P_{i} Q_{i}=-\alpha_{i i} / \eta_{i i}$
} 


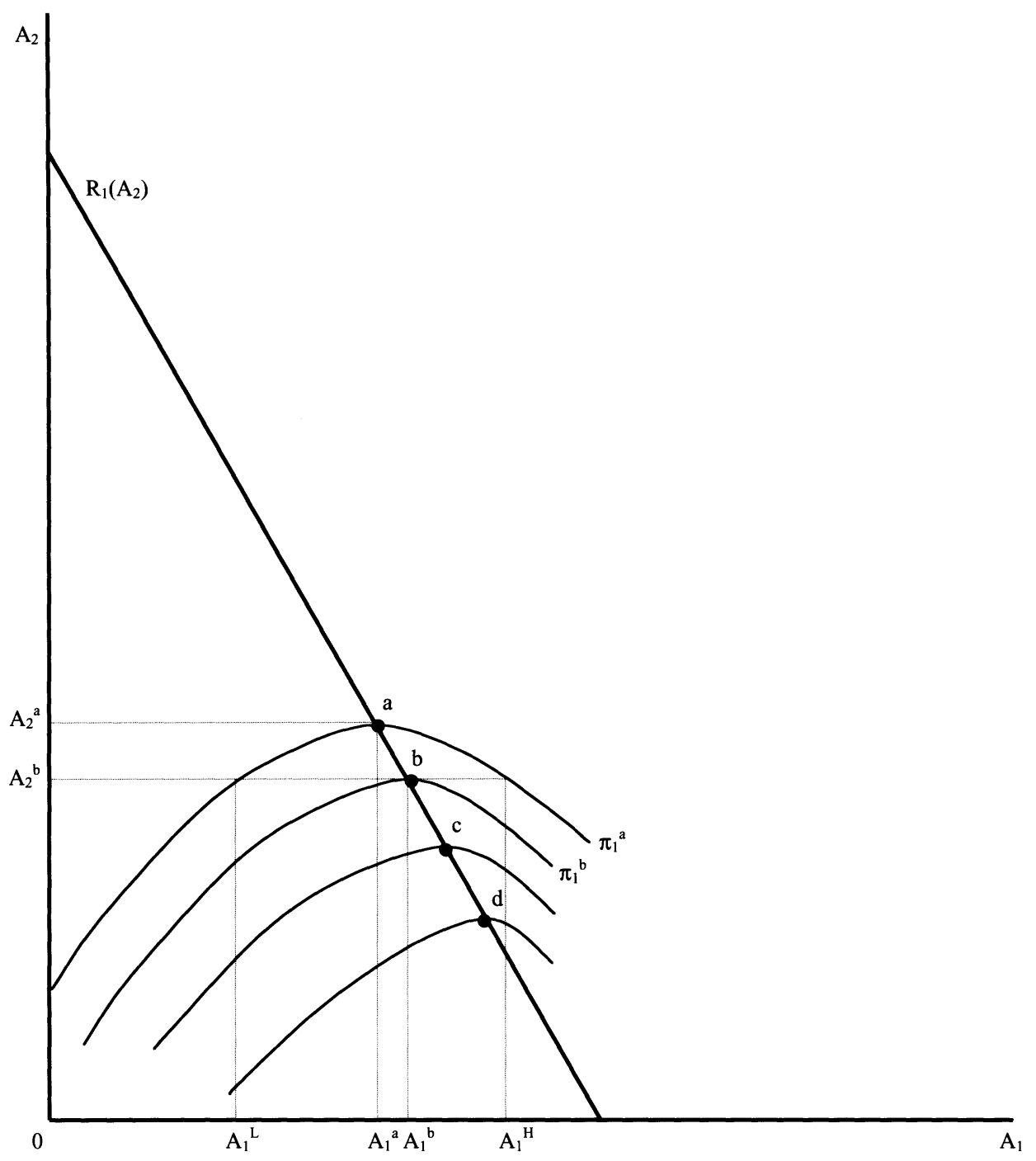

Figure 1. Reaction curves and isoprofit contours

Such reaction functions will usually be downward sloping. In this case, the slope of the reaction function for group 1 is

$$
\begin{aligned}
\frac{\partial A_{1}^{*}}{\partial A_{2}}= & \frac{\left(1+\epsilon_{1}\right)\left[\alpha_{12}\left(\epsilon_{2}-\eta_{22}\right)+\alpha_{22} \eta_{12}\right]}{D-F} \\
& \times \frac{A_{1}}{A_{2}} .
\end{aligned}
$$

This expression will be negative for most reasonable elasticity values. ${ }^{11}$ In particular, it

\footnotetext{
11 The conditions for a positive denominator of equation (26), i.e., $D>F$, include

$$
\epsilon_{1}>\frac{\alpha_{11}+\eta_{11}}{1-\alpha_{11}} \text { and } \frac{\epsilon_{2}-\eta_{22}}{\eta_{12}}>\frac{\eta_{21}+\alpha_{21}\left(1+\epsilon_{1}\right)}{\epsilon_{1}-\eta_{11}-\alpha_{11}\left(1+\epsilon_{1}\right)} \text {. }
$$
}

The first of these conditions will be met when $\left|\eta_{11}\right|>\alpha_{11}$ and $\alpha_{11}<1$, which make the RHS of the inequality negative; $\alpha_{11}<1$ is implied by our maintained assumption of diminishing marginal can be seen that when the cross-commodity advertising effect is large relative to the cross-commodity price feedback effect, the reaction function will slope down.

The noncooperative equilibrium is given by the intersection of the reaction curves for the two groups of producers. Figure 1 shows

returns to advertising. The second condition will generally be met under likely elasticity conditions: $\left|\eta_{22}\right|>\eta_{12}$ makes the LHS greater than one, and $\alpha_{11}>\left|\alpha_{21}\right|$ and $\left|\eta_{11}\right|>\eta_{21}$ make the RHS less than one. The sign of the numerator of the slope term will be determined by the inequality

$$
-\frac{\alpha_{12}}{\eta_{12}}>\frac{\alpha_{22}}{\epsilon_{2}-\eta_{22}} \text {. }
$$

When the above inequality holds as written, and the denominator is positive (i.e., $D>F$ ), the reaction function slopes down. When the inequality is reversed, the reaction function slopes up, and advertising expenditures are strategic complements rather than substitutes. 


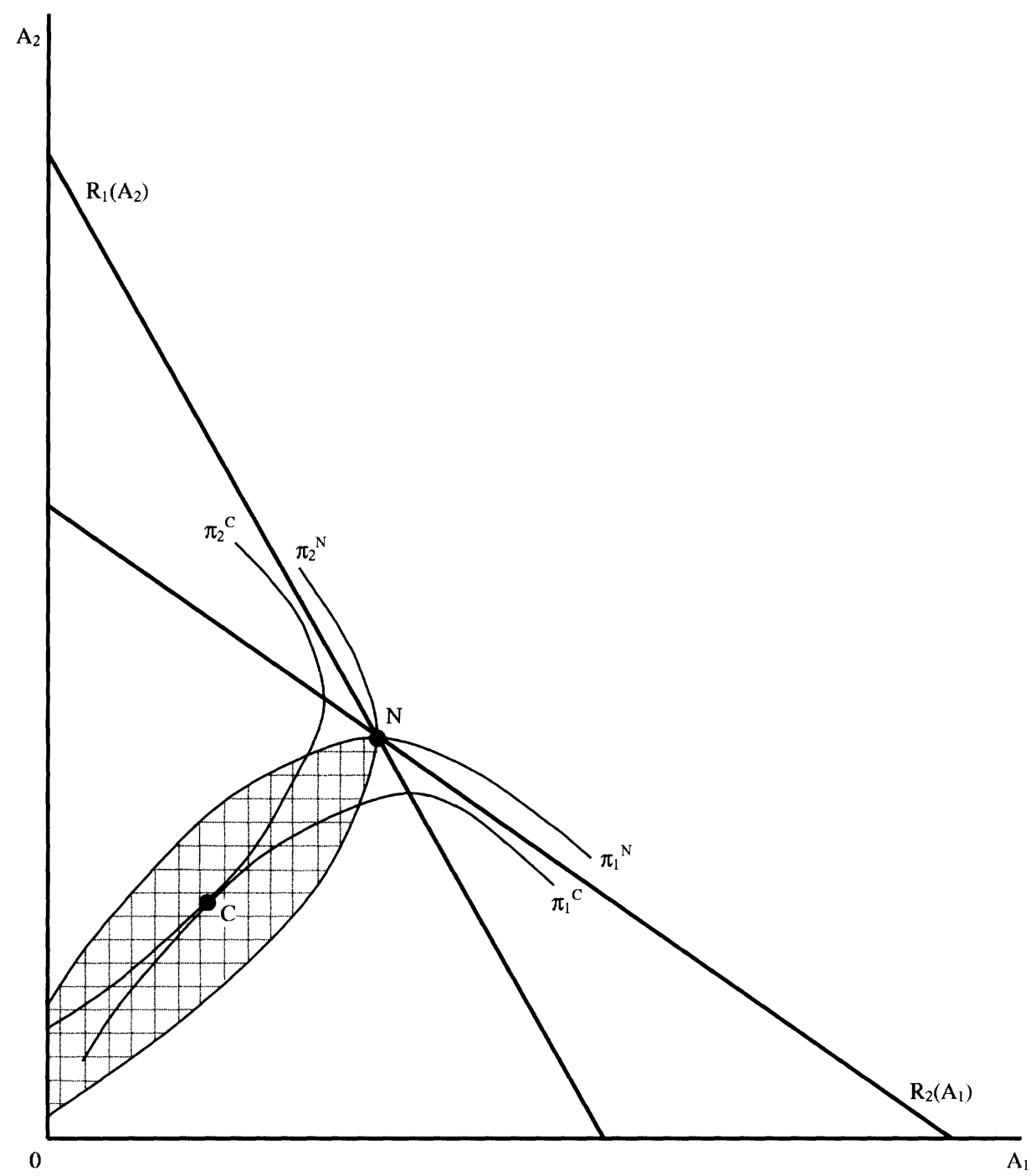

Figure 2. Noncooperative and cooperative equilibria

the reaction curve for producers of good 1 , $R_{1}\left(A_{2}\right)$. At any point along $R_{1}\left(A_{2}\right)$, for a given advertising expenditure by group 2 $\left(A_{2}\right)$, the corresponding quantity of advertising by group $1, A_{1}=R_{1}\left(A_{2}\right)$, measured along the horizontal axis, maximizes the profits to producers of good 1. Thus, for instance, at point $a$, the profit-maximizing advertising expenditure for group 1 is $A_{1}^{a}$ when group 2's advertising expenditure is $A_{2}^{a}$.

The isoprofit contour, $\pi_{1}^{a}$, is the locus of combinations of $A_{1}$ and $A_{2}$ that would yield the same profit to producers of good 1 as earned at point $a$. This curve is concave, with a maximum at point $a$ (by definition). For every point along $R_{1}\left(A_{2}\right)$, a similar isoprofit contour reaches its maximum as it passes through the reaction function, such as the curves through points $b, c$, and $d$, which represent successively higher profits for producers of good 1 (because they are associated with lower advertising expenditures by producers of good 2).

Figure 2 replicates figure 1 and includes the corresponding reaction curve of group 2, $R_{2}\left(A_{1}\right)$, and two isoprofit contours for group 2. A noncooperative equilibrium in this situation is defined by the intersection of the two reaction curves, as depicted by point $N$ in figure 2. At this point, each group's advertising expenditure is optimized, given the other group's expenditure, a stable Nash equilibrium. The isoprofit contours passing through point $N$ in figure 2 indicate that producers of good 1 are obtaining profit of $\pi_{1}^{N}$, and producers of good 2 are obtaining profit of $\pi_{2}^{N}$. 
The cross-hatched area formed by the two isoprofit frontiers is a lens of mutual advantage, which contains all of the combinations of $A_{1}$ and $A_{2}$, where both groups of producers could be made better off relative to the Nash equilibrium at point $N$, if they both reduced their advertising expenditures.

\section{Cooperative Advertising with Lump-Sum Funding}

In the cooperative case, $A_{1}$ and $A_{2}$ are chosen jointly by the two producer groups to maximize the sum of their profits, and the first-order conditions given in equation (14) reduce to

$$
\begin{aligned}
A_{1}^{C}= & P_{1} Q_{1}(\cdot)\left[\frac{\alpha_{11}\left(\epsilon_{2}-\eta_{22}\right)+\alpha_{21} \eta_{12}}{D}\right] \\
& +P_{2} Q_{2}(\cdot)\left[\frac{\alpha_{21}\left(\epsilon_{1}-\eta_{11}\right)+\alpha_{11} \eta_{21}}{D}\right] \\
A_{2}^{C}= & P_{1} Q_{1}(\cdot)\left[\frac{\alpha_{12}\left(\epsilon_{2}-\eta_{22}\right)+\alpha_{22} \eta_{12}}{D}\right] \\
& +P_{2} Q_{2}(\cdot)\left[\frac{\alpha_{22}\left(\epsilon_{1}-\eta_{11}\right)+\alpha_{12} \eta_{21}}{D}\right] .
\end{aligned}
$$

To determine explicit solutions for $A_{1}$ and $A_{2}$, specific demand functions must be specified, and the price terms must be substituted out of the expressions to obtain solutions for $A_{1}^{C}$ and $A_{2}^{C}$ as functions of the parameters of the model.

In this cooperative setting, where producer groups work together to maximize the sum of their profits, the optimum will be found at a tangency between isoprofit contours. For instance, in figure 2 , the solution might be at a point such as $C$, where group 1 would earn $\pi_{1}^{C}>\pi_{1}^{N}$, and group 2 would earn $\pi_{2}^{C}>\pi_{2}^{N}$, which represents a Pareto improvement relative to point $N$. The locus of such tangency points is the contract curve. Points on that curve and inside the lens represent Pareto improvements relative to point $N$. Other points on the contract curve outside the lens achieve higher profits for one group at the expense of the other group and might entail higher total profits than any point within the lens (that is, the cooperative optimum might lie outside the lens). This would be a case where maximizing the total profit would involve a reduction in profit for one of the groups relative to point $N$, a potential Pareto improvement. To be feasible, this would require a lump-sum transfer to compensate the group experiencing a loss.

\section{Advertising Funded by an}

Ad Valorem Check-Off

Solutions for the optimal tax rates $\left(t_{1}\right.$ and $t_{2}$ ) for the case of $m=n=2$ and advertising funded by an ad valorem check-off $\left(A_{i}=\right.$ $\left.t_{i} P_{i} Q_{i}\right)$ are

$$
\begin{array}{r}
t_{1}=\frac{\left[\begin{array}{r}
\alpha_{11}\left[\alpha_{22}\left(1+\epsilon_{2}\right)+\eta_{22}-\epsilon_{2}\right] \\
-\alpha_{21}\left[\alpha_{12}\left(1+\epsilon_{2}\right)+\eta_{12}\right]
\end{array}\right]}{\left[\begin{array}{r}
-\eta_{11}\left[\alpha_{22}\left(1+\epsilon_{2}\right)+\eta_{22}-\epsilon_{2}\right] \\
+\eta_{21}\left[\alpha_{12}\left(1+\epsilon_{2}\right)+\eta_{12}\right.
\end{array}\right]} \\
t_{2}=\frac{\left[\begin{array}{r}
\alpha_{22}\left[\alpha_{11}\left(1+\epsilon_{1}\right)+\eta_{11}-\epsilon_{1}\right] \\
-\alpha_{12}\left[\alpha_{21}\left(1+\epsilon_{1}\right)+\eta_{21}\right]
\end{array}\right]}{\left[\begin{array}{r}
-\eta_{22}\left[\alpha_{11}\left(1+\epsilon_{1}\right)+\eta_{11}-\epsilon_{1}\right] \\
+\eta_{12}\left[\alpha_{21}\left(1+\epsilon_{1}\right)+\eta_{21}\right]
\end{array}\right]}
\end{array}
$$

The tax rates depend generally on the key parameters in the same ways as advertising expenditures do. Notice, however, that the two tax rates (which, as it happens, are also the advertising intensities $-t_{i}=A_{i} / P_{i} Q_{i}$ ) are independent of one another, and of prices and quantities: they depend only on the elasticities. The same is also true of the advertising intensities implied by equations (20) and (21) in the case of lump-sum funding. In both cases, the optimal advertising intensities are constant for the constant-elasticity functional form considered here. For other functional forms, advertising intensities will vary as the elasticity values vary.

Because the two goods are gross substitutes in consumption, the collection of a check-off on good 1 results in an increase in its price, and consequently an increase in the demand for good 2-each group benefits when the other taxes its own market. On the other hand, when a group spends its tax money on advertising the other group is disadvantaged through beggar-thy-neighbor effects. For a given amount of advertising, the tax collection effect mitigates the beggarthy-neighbor effect and might even outweigh it, turning goods that were strategic advertising substitutes under lump-sum funding into strategic advertising complements under check-off funding. In general, however, the effect of shifting of the cost of advertising to consumers is expected to be more important than any cross-commodity implications of the check-off funding (versus lump-sum funding) so that the net effect of check-off funding is to cause each group to advertise 
Table 1. Elasticities of Demand with Respect to Price and Advertising

\begin{tabular}{|c|c|c|c|c|c|c|}
\hline \multirow{3}{*}{$\begin{array}{l}\text { Elasticity of } \\
\text { Demand for }\end{array}$} & \multicolumn{6}{|c|}{ With Respect to } \\
\hline & \multicolumn{4}{|c|}{ Price of } & \multicolumn{2}{|c|}{ Advertising of } \\
\hline & Beef & Pork & Poultry & Other & Beef & Pork \\
\hline Beef & -0.56 & 0.10 & 0.05 & 0.41 & 0.00050 & -0.00023 \\
\hline Pork & 0.23 & -0.69 & 0.04 & 0.42 & -0.00043 & 0.00050 \\
\hline Poultry & 0.21 & 0.07 & -0.33 & 0.05 & -0.00043 & -0.00023 \\
\hline
\end{tabular}

Source: Price elasticities were taken from Brester and Schroeder (p. 977). Advertising elasticities were derived from authors' calculations.

more, exacerbating the beggar-thy-neighbor problem. This conjecture is evaluated in the simulation experiments, reported below.

\section{Simulation Results: U.S. Beef and Pork Promotion}

In the two-good case, our theoretical results suggest that each producer group is likely to advertise to a greater extent than the other would prefer, and the total producer surplus will be less than if the groups were amalgamated into one (or were organized otherwise to act so as to maximize the sum of producer surpluses without regard to its distribution). We use numerical simulation methods to explore the potential importance of these cross-commodity effects, and the differences between the single-commodity and joint optima in a model of the market for meat. Elasticities and other parameters were defined to represent U.S. beef, pork, poultry (combining chicken and turkey), and a fourth composite good representing "all other goods." Our focus is on the meat industry, and we treat the price of the fourth good as being exogenous. Hence, we only need to model explicitly the markets for the three meats.

\section{Parameter Values and Model Specification}

Base values for own-price elasticities of supply for beef and pork were taken from Wohlgenant, and we assumed that the supply elasticity for poultry would be equal to that of pork: i.e., $\epsilon_{B}=0.15, \epsilon_{P}=$ $0.40, \epsilon_{C}=0.40$. Table 1 shows a base set of values for elasticities of demand with respect to prices and advertising, for U.S. beef $(B)$, pork $(P)$, poultry $(C)$, and "other" goods $(O)$. The price elasticities were taken from Brester and Schroeder. The advertising elasticities were developed in consideration of the estimates in the literature-including Ward and Lambert, Wohlgenant, Brester and Schroeder, Kinnucan et al., Piggott (1997), and Coulibaly and Brorsen - which reveals a large range of advertising elasticities and considerable fragility of individual estimates. We defined elasticities such that the values would be mutually consistent and would imply advertising intensities in the range of the actual intensities. First, we set the own-advertising elasticity of demand for beef equal to 0.0005 . Then, to define values that would be mutually consistent, we assumed that the cross-commodity elasticities of demand with respect to beef advertising would be equal for pork and poultry, assumed zero effect on the "other" good, and imposed the adding-up restriction to solve for the cross-elasticities; similarly for pork advertising. Table 2 shows the actual retail prices and quantities consumed, estimated advertising expenditures in 1998, and the implied advertising intensities.

The elasticity values and price and quantity data for 1998 were used to initialize supply and demand functions, of the constant elasticity form, for beef, pork, and poultry, treating the nonmeat good's price and total spending on the four goods as exogenous. Given these demand and supply specifications, the producer groups' profits were defined as $\pi_{i}=$ $P_{i} Q_{i} /\left(1+\epsilon_{i}\right)$, for $i=B, P$, and $C$. We used the Solver routine in Excel to find the noncooperative and cooperative equilibria.

\section{Results and Discussion}

Table 3 shows the optimal advertising expenditures for each of the two producer groups, and the corresponding advertising intensities and benefits from advertising under three 
Table 2. U.S. Meat Consumption, Price, and Generic Advertising Expenditures, 1998

\begin{tabular}{lcccc}
\hline Meat & $\begin{array}{c}\text { Consumption } \\
\text { (million pounds) }\end{array}$ & $\begin{array}{c}\text { Price } \\
\text { (\$ per pound) }\end{array}$ & $\begin{array}{c}\text { Advertising } \\
\text { Expenditure } \\
\text { (\$ million) }\end{array}$ & $\begin{array}{c}\text { Advertising } \\
\text { Intensity } \\
\text { (percent) }\end{array}$ \\
\hline Beef & $18,412.10$ & 2.77 & 25.51 & 0.05 \\
Pork & $14,207.01$ & 2.43 & 13.79 & 0.04 \\
Poultry & $24,600.42$ & 1.03 & 0 & 0 \\
\hline
\end{tabular}

Source: Prices and quantities were provided by Nick Piggott in an updated version of the series used in his dissertation (Piggott 1997). Advertising expenditures were estimated by multiplying the actual advertising intensities from 1994 to the total revenue for 1998.

behavioral assumptions. Under noncooperative competition, advertising expenditures are chosen independently. Under cooperation between the producer groups, advertising expenditures are chosen jointly to maximize the sum of profits to either beef and pork producers, or beef, pork, and poultry produc- ers. In addition, we show the sums across the two groups of advertising expenditures (and the corresponding aggregate advertising intensity, given by the sum of the beef and pork advertising expenditures as a percentage of the combined value of beef and pork sales) and the changes in total prof-

Table 3. Effects of Funding Methods and Behavioral Assumptions on Optimal Advertising

\begin{tabular}{|c|c|c|c|}
\hline $\begin{array}{l}\text { Variable } \\
\text { of } \\
\text { Interest }\end{array}$ & $\begin{array}{l}\text { Noncooperative } \\
\text { Competition }\end{array}$ & $\begin{array}{l}\text { Beef and Pork } \\
\text { Producers } \\
\text { Cooperate }\end{array}$ & $\begin{array}{l}\text { Beef, Pork, and } \\
\text { Poultry Producers } \\
\text { Cooperate }\end{array}$ \\
\hline \multicolumn{4}{|l|}{ Lump-sum funding } \\
\hline \multicolumn{4}{|c|}{ Optimal advertising expenditure ( $\$$ million/year) } \\
\hline Beef producers & 32.44 & 23.47 & 12.48 \\
\hline Pork producers & 13.28 & 0.00 & 0.00 \\
\hline Total beef and pork & 45.72 & 23.47 & 12.48 \\
\hline \multicolumn{4}{|c|}{ Optimal advertising intensities (percent of revenue) } \\
\hline Beef producers & 0.06 & 0.05 & 0.02 \\
\hline Pork producers & 0.04 & 0.00 & 0.00 \\
\hline Total beef and pork & 0.05 & 0.03 & 0.01 \\
\hline \multicolumn{4}{|c|}{ Benefits from advertising ${ }^{\text {a }}$ ( $\$$ million/year) } \\
\hline Beef producers & 246 & 656 & 647 \\
\hline Pork producers & 33 & -319 & -313 \\
\hline Poultry producers & -291 & -35 & -28 \\
\hline Beef and pork producers & 279 & 338 & 334 \\
\hline All producers & -13 & 303 & 306 \\
\hline \multicolumn{4}{|l|}{ Ad valorem check-off funding } \\
\hline \multicolumn{4}{|c|}{ Optimal advertising expenditure (\$ million/year) } \\
\hline Beef producers & 41.77 & 31.43 & 17.59 \\
\hline Pork producers & 21.47 & 0.00 & 0.00 \\
\hline Total beef and pork & 63.24 & 31.43 & 17.59 \\
\hline \multicolumn{4}{|c|}{ Optimal advertising intensities (percent of revenue) } \\
\hline Beef producers & 0.08 & 0.06 & 0.03 \\
\hline Pork producers & 0.06 & 0.00 & 0.00 \\
\hline Total beef and pork & 0.07 & 0.04 & 0.02 \\
\hline \multicolumn{4}{|c|}{ Benefits from advertising ${ }^{\mathrm{a}}$ (\$ million/year) } \\
\hline Beef producers & 248 & 647 & 639 \\
\hline Pork producers & 38 & -304 & -299 \\
\hline Poultry producers & -296 & -48 & -42 \\
\hline Beef and pork producers & 287 & 343 & 339 \\
\hline All producers & -9 & 294 & 297 \\
\hline
\end{tabular}

a Measured as the change in profit relative to the equilibrium with beef and pork advertising approximately equal to zero. 
its relative to a scenario without any generic advertising. These effects are shown for two types of funding: lump-sum funding in the upper half of the table, and funding by ad valorem check-offs in the lower half of the table. The simulated advertising intensities (and expenditures) in table 3 under noncooperative behavior are similar to the observed values given in table 2 .

The results in table 3 show the quantitative importance of the beggar-thy-neighbor effects. First, to see the effects of different forms of competition under lump-sum funding, consider the upper half of the table. Beef producers would spend much more on advertising ( $\$ 32$ million, $0.06 \%$ of revenue) under noncooperative competition than the amount that would maximize joint profits with pork producers ( $\$ 23$ million, $0.05 \%$ of revenue) or, even more so, the amount that would maximize joint profits with pork and poultry producers ( $\$ 12$ million, $0.02 \%$ of revenue). For pork producers the relationship is in the same direction but more pronounced: they would spend a significant sum on advertising under noncooperative competition ( $\$ 13$ million, $0.04 \%$ of revenue) but would not advertise at all in either of the cooperative scenarios. Considering the combined expenditure of beef and pork producers, in the noncooperative case collectively they would spend $\$ 46$ million $(0.05 \%$ of revenue). In the cooperative case they would spend $\$ 23$ million $(0.03 \%$ of revenue) to maximize their combined profits ignoring poultry producers, or $\$ 12$ million $(0.01 \%$ of revenue) if they maximized joint profits including poultry producer profits. Looking at the lower half of the table, the same pattern across behavioral assumptions can be seen when advertising is funded by an ad valorem check-off.

Second, compare the different types of funding. The optimal expenditure on advertising is much greater when it is funded by a check-off (and part of the costs are borne by consumers) than when it is funded as a lump sum (with all of the costs borne by producers), regardless of the assumptions made about producer behavior, for both groups and in aggregate. In the noncooperative case, check-off funding implies total expenditure of $\$ 63$ million on beef and pork promotion, and in the cooperative cases, $\$ 31$ million when poultry producer profits are not considered or $\$ 18$ million when they are -in each case, substantially more than under lump-sum funding.
Lastly, table 3 includes figures for the annual changes in producer profits (measured as producer surplus) relative to a noadvertising base for each combination of funding method and assumption about producer behavior. In this part of the table it can be seen that beef and pork producer profits from advertising come at least partly at the expense of poultry producers. In the noncooperative case there is a net loss to meat producers as a group (the losses to poultry producers exceed the gains to beef and pork producers), $\$ 13$ million per year under lump-sum funding or $\$ 9$ million per year under check-off funding. Compared with the noncooperative scenario, in either of the cooperative scenarios, profits are greater for beef producers and for the aggregate of beef and pork producers or the aggregate including poultry producers as well, but lower for pork producers - hence, this cooperative outcome would require a lump-sum transfer from beef producers to pork producers (or to pork producers and poultry producers) to be feasible.

Comparing the cooperative and noncooperative scenarios, the difference in total profits (across all producers) from generic advertising is a measure of the producer loss from beggar-thy-neighbor behavior: under lump-sum funding, a loss of $\$ 13$ million per year compared with a potential gain of \$306 million per year; under check-off funding, a loss of $\$ 9$ million per year compared with a potential gain of $\$ 297$ million per year.

\section{Alternative Parameter Values}

The results in table 3 were based on some best-estimate parameter values. To explore the model relationships further, we conducted some limited experiments with the advertising elasticities in the case of ad valorem check-off funding. Table 4 shows the differences in optimal beef advertising checkoff rates (or advertising intensities) implied by the thirty-two different elasticity combinations obtained by using either the initial value or half the initial value for each of the other five advertising elasticities, while holding the own-advertising elasticity of demand for beef (i.e., $\alpha_{B B}$ ) constant at its initial value. Each column corresponds to a different set of values for cross-elasticities with respect to beef advertising, and each row corresponds to 
Table 4. Sensitivity of Noncooperative Beef Check-off Rates to Advertising Elasticity Values

\begin{tabular}{|c|c|c|c|c|c|c|}
\hline & & & \multicolumn{4}{|c|}{$\alpha_{B B}=0.00050^{*}$} \\
\hline & & & \multicolumn{2}{|c|}{$\alpha_{P B}=-0.00043^{*}$} & \multicolumn{2}{|c|}{$\alpha_{P B}=-0.00021$} \\
\hline & & & $\begin{array}{c}\alpha_{C B} \\
=-0.00043^{*}\end{array}$ & $\begin{array}{c}\alpha_{C B} \\
=-0.00021 \\
\end{array}$ & $\begin{array}{c}\alpha_{C B} \\
=-0.00043^{*}\end{array}$ & $\begin{array}{c}\alpha_{C B} \\
=-0.00021\end{array}$ \\
\hline \multirow{4}{*}{$\begin{array}{l}\alpha_{P P} \\
=0.00050^{*}\end{array}$} & & $\alpha_{C P}=-0.00023^{*}$ & 0.0819 & 0.0849 & 0.0858 & 0.0888 \\
\hline & $=-0.00023^{*}$ & $\alpha_{C P}=-0.00011$ & 0.0819 & 0.0849 & 0.0858 & 0.0888 \\
\hline & $\alpha_{B P}$ & $\alpha_{C P}=-0.00023^{*}$ & 0.0819 & 0.0849 & 0.0858 & 0.0888 \\
\hline & $=-0.00011$ & $\alpha_{C P}=-0.00011$ & 0.0819 & 0.0849 & 0.0858 & 0.0888 \\
\hline \multirow{4}{*}{$\begin{array}{l}\alpha_{P P} \\
=0.00025\end{array}$} & $\alpha_{B P}$ & $\alpha_{C P}=-0.00023^{*}$ & 0.0819 & 0.0849 & 0.0858 & 0.0888 \\
\hline & $=-0.00023^{*}$ & $\alpha_{C P}=-0.00011$ & 0.0819 & 0.0849 & 0.0858 & 0.0888 \\
\hline & $\alpha_{B P}$ & $\alpha_{C P}=-0.00023^{*}$ & 0.0819 & 0.0849 & 0.0858 & 0.0888 \\
\hline & $=-0.00011$ & $\alpha_{C P}=-0.00011$ & 0.0819 & 0.0849 & 0.0858 & 0.0888 \\
\hline
\end{tabular}

Note: * indicates the base parameter values from table 1.

a different set of values for elasticities with respect to pork advertising. ${ }^{12}$

The noncooperative beef check-off rates in table 4 are generally not very sensitive to advertising elasticities. Specifically, for a given set of elasticities of demand with respect to beef advertising, changes in the elasticities of demand with respect to pork advertising do not affect the optimal noncooperative beef check-off rate (i.e., the intensities in each column are all equal). And, comparing across columns, when we hold the own-advertising elasticity (i.e., $\alpha_{B B}$ ) constant at its base value, halving either of the cross-commodity elasticities (i.e., $\alpha_{P B}$ or $\alpha_{C B}$ ) gives rise to a small increase in the optimal intensity, which increases by less than one-tenth, even when we halve both the cross-elasticities.

The optimal beef advertising intensities for the case where beef, pork, and poultry producers cooperate to maximize the sum of their profits are shown in table 5 for elasticity values that correspond to those used in table 4 . The cooperative advertising intensities are always smaller than their noncooperative counterparts, and more sensitive to elasticities-especially the elasticities of demand with respect to beef advertising, as can be seen by comparing across columns in table 5. When the parameters are at their base values, the cooperative intensity is $0.0342 \%$ (compared with $0.0819 \%$ in the

\footnotetext{
${ }^{12}$ Note that when we allow the elasticities to vary independently, we are no longer imposing the restriction that the weighted average of the elasticities must sum to zero, and we run a risk of defining a nonsensical combination of elasticities. To minimize this type of problem we held the own-advertising elasticity constant for beef and reduced the others in turn.
}

noncooperative scenario). Halving either of the cross-commodity elasticities of demand with respect to beef advertising (i.e., $\alpha_{P B}$ or $\alpha_{C B}$ ) results in a substantial increase in the intensity, to about $0.06 \%$; halving both results in a cooperative intensity of $0.0853 \%$, quite close to its noncooperative counterpart of $0.0888 \%$. Not surprisingly, the cooperative advertising intensities are larger when the negative direct effects of beef advertising in the pork and poultry markets are reduced. In other words, the beggar-thy-neighbor effects are smaller when the direct cross-market effects of beef advertising are smaller. The cooperative intensities also vary a little more than their noncooperative counterparts when different values are used for the elasticities with respect to pork advertising (i.e., here, intensities vary among rows of a column, as well as across columns), but as in the noncooperative case, these effects are comparatively small.

The entries in table 6 are ratios of the optimal beef advertising intensity under noncooperative behavior to the corresponding intensity under cooperative behavior (maximizing the sum of profits to beef, pork, and poultry producers), for each elasticity combination. The extent to which this ratio exceeds one indicates the degree of overspending on advertising from the collective viewpoint. The ratio is essentially constant within each column of table 6 but varies quite substantially across columns; hence the degree of overspending is not sensitive to elasticities of demand with respect to pork advertising but is sensitive to elasticities of demand with respect to beef advertising. In 
Table 5. Sensitivity of Beef Check-off Rates to Advertising Elasticity Values, for the Case Where Beef, Pork, and Poultry Producers Cooperate

\begin{tabular}{|c|c|c|c|c|c|c|}
\hline & & & \multicolumn{4}{|c|}{$\alpha_{B B}=0.00050^{*}$} \\
\hline & & & \multicolumn{2}{|c|}{$\alpha_{P B}=-0.00043^{*}$} & \multicolumn{2}{|c|}{$\alpha_{P B}=-0.00021$} \\
\hline & & & $\begin{array}{c}\alpha_{C B} \\
=-0.00043^{*}\end{array}$ & $\begin{array}{c}\alpha_{C B} \\
=-0.00021\end{array}$ & $\begin{array}{c}\alpha_{C B} \\
=-0.00043^{*}\end{array}$ & $\begin{array}{c}\alpha_{C B} \\
=-0.00021\end{array}$ \\
\hline \multirow{4}{*}{$\begin{array}{l}\alpha_{P P} \\
=0.00050^{*}\end{array}$} & $\alpha_{B P}$ & $\alpha_{C P}=-0.00023^{*}$ & 0.0342 & 0.0601 & 0.0594 & 0.0853 \\
\hline & $=-0.00023^{*}$ & $\alpha_{C P}=-0.00011$ & 0.0343 & 0.0601 & 0.0596 & 0.0853 \\
\hline & $\alpha_{B P}$ & $\alpha_{C P}=-0.00023^{*}$ & 0.0338 & 0.0597 & 0.0594 & 0.0853 \\
\hline & $=-0.00011$ & $\alpha_{C P}=-0.00011$ & 0.0337 & 0.0596 & 0.0594 & 0.0853 \\
\hline \multirow{4}{*}{$\begin{array}{l}\alpha_{P P} \\
=0.00025\end{array}$} & $\alpha_{B P}$ & $\alpha_{C P}=-0.00023^{*}$ & 0.0340 & 0.0599 & 0.0594 & 0.0853 \\
\hline & $=-0.00023^{*}$ & $\alpha_{C P}=-0.00011$ & 0.0342 & 0.0600 & 0.0595 & 0.0853 \\
\hline & $\alpha_{B P}$ & $\alpha_{C P}=-0.00023^{*}$ & 0.0338 & 0.0598 & 0.0593 & 0.0853 \\
\hline & $=-0.00011$ & $\alpha_{C P}=-0.00011$ & 0.0340 & 0.0599 & 0.0594 & 0.0853 \\
\hline
\end{tabular}

Note: ${ }^{*}$ indicates the base parameter values from table 1

the base case (the left-hand column), the noncooperative advertising intensity is 2.4 times the cooperative optimum - roughly speaking, overspending by $140 \%$. If we halve either of the cross-elasticities, the extent of overspending is reduced to $40 \%$ and if we halve both of them, it is reduced to $4 \%$.

Clearly, the relative sizes of the direct effects of advertising in the different markets are important in determining the beggarthy-neighbor effect. When the direct negative effects of beef advertising are small relative to the own-market effects (i.e., the last column), the beggar-thy-neighbor effects are small. But to create these scenarios with relatively small cross-commodity effects we had to abandon our adding-up condition within the group of meats and implicitly introduce a relatively large negative cross-commodity effect of beef advertising on the nonmeat group. Even though some of the resulting elasticity combinations might not be plausible, the general sensitivity of the beggar-thyneighbor element to the relative sizes of ownand cross-commodity advertising elasticities adds to our reasons for wanting more reliable estimates of these elasticities.

\section{Conclusion}

Marketing-order type arrangements for collective action are predicated on the view that there are market failures in the provision of certain types of public or collective goods. In-principle arguments support collective action in the provision of things such as applied research, grades and stan-

Table 6. Sensitivity of Beggar-Thy-Neighbor Effects in Beef Advertising to the Sizes of the Advertising Elasticities

\begin{tabular}{|c|c|c|c|c|c|c|}
\hline & & & \multicolumn{4}{|c|}{$\alpha_{B B}=0.00050^{*}$} \\
\hline & & & \multicolumn{2}{|c|}{$\alpha_{P B}=-0.00043^{*}$} & \multicolumn{2}{|c|}{$\alpha_{P B}=-0.00021$} \\
\hline & & & $\begin{array}{c}\alpha_{C B} \\
=-0.00043^{*}\end{array}$ & $\begin{array}{c}\alpha_{C B} \\
=-0.00021\end{array}$ & $\begin{array}{c}\alpha_{C B} \\
=-0.00043^{*}\end{array}$ & $\begin{array}{c}\alpha_{C B} \\
=-0.00021\end{array}$ \\
\hline \multirow{4}{*}{$\begin{array}{l}\alpha_{P P} \\
=0.00050^{*}\end{array}$} & $\alpha_{B P}$ & $\alpha_{C P}=-0.00023^{*}$ & 2.3946 & 1.4112 & 1.4437 & 1.0403 \\
\hline & $=-0.00023^{*}$ & $\alpha_{C P}=-0.00011$ & 2.3834 & 1.4113 & 1.4402 & 1.0408 \\
\hline & $\alpha_{B P}$ & $\alpha_{C P}=-0.00023^{*}$ & 2.4243 & 1.4225 & 1.4435 & 1.0412 \\
\hline & $=-0.00011$ & $\alpha_{C P}=-0.00011$ & 2.4252 & 1.4233 & 1.4432 & 1.0412 \\
\hline \multirow{4}{*}{$\begin{array}{l}\alpha_{P P} \\
=0.00025\end{array}$} & $\alpha_{B P}$ & $\alpha_{C P}=-0.00023^{*}$ & 2.4064 & 1.4158 & 1.4445 & 1.0412 \\
\hline & $=-0.00023^{*}$ & $\alpha_{C P}=-0.00011$ & 2.3961 & 1.4152 & 1.4411 & 1.0409 \\
\hline & $\alpha_{B P}$ & $\alpha_{C P}=-0.00023^{*}$ & 2.4203 & 1.4183 & 1.4473 & 1.0413 \\
\hline & $=-0.00011$ & $\alpha_{C P}=-0.00011$ & 2.4095 & 1.4176 & 1.4434 & 1.0411 \\
\hline
\end{tabular}

Note: ${ }^{*}$ indicates the base parameter values from table 1. 
dards, and market information. It is less clear that, absent government intervention, the private sector would underinvest from society's viewpoint in generic commodity advertising and promotion. Measurement issues aside, some of the potential effects of commodity promotion are ill-defined with current methods (those on consumer welfare) and others are ambiguous (those on producers of related goods). Nevertheless, the policy prescription has been to create institutional arrangements for collective action in commodity promotion, funded by check-offs, mandated by plebiscite.

Even if there were an underinvestment otherwise, our analysis indicates that the cure (collective action under mandated programs) may be worse than the disease (individual underinvestment from the collective viewpoint). Once a marketing order is established, individual producer groups are likely to over- or underinvest in promotion from the viewpoint of a larger group, including producers of related commodities. Whether the interaction effects are positive or negative depends on elasticities, and plausible elasticity values are consistent with either case. In a case of strategic complements, there is an underinvestment in advertising from the point of view of producers as a group. How $\rightarrow$ ever, strategic substitutes are more likely, and in this case, excessive advertising is an implication of noncooperative decision $\rightarrow$ making between competing producer groups. Finally, any tendency toward excessive advertising is exacerbated under check $\rightarrow$ off funding, whereby producers shift some of the costs of financing promotion onto consumers.

In our empirical example, the beggar-thy $\rightarrow$ neighbor effects were large. Our results imply that more care should be taken in authorizing generic promotion programs. In determining whether to approve particular programs, specific consideration ought to be given to the extent of the beggar-thy-neighbor aspect, if the relevant criterion is net benefits to all producers. The existence of beggar-thyneighbor effects need not mean a program should be disallowed-a program may still yield net benefits to producers as a group, even though it involves too much promotion and lower benefits than if the interests of all affected producers had been considered. In such a situation, the question is how to achieve a more nearly socially optimal outcome. Given the difficulty of measuring the effects of promotion, rather than devise regulatory solutions, we might seek to structure the institutions such that effects were more nearly fully internalized.

[Received April 2000;
accepted March 2001.]

\section{References}

Alston, J.M., H.F. Carman, and J.A. Chalfant. "Evaluating Primary Product Promotion: The Returns to Generic Advertising by a Producer Cooperative in a Small, Open Economy." Promotion in the Marketing Mix: What Works, Where and Why. E.W. Goddard and D.S. Taylor, eds., pp. 145-67. Guelph Canada: University of Guelph, 1994.

Alston, J.M., J.A. Chalfant, and N.E. Piggott. "Advertising and Consumer Welfare." Mimeo, Department of Agr. and Resour. Econ., University of California, Davis, 1998.

. "The Incidence of the Costs and Benefits of Generic Advertising." Amer. J. Agr. Econ. 82(August 2000):665-71.

Basmann, R.L. "A Theory of Demand with Variable Consumer Preferences." Econometrica 24(January 1956):47-58.

Becker, G.S., and K.M. Murphy. "A Simple Theory of Advertising as a Good or Bad." Quart. J. Econ. 108(November 1993):941-64.

Brester, G.W., and T.C. Schroeder. "The Impacts of Brand and Generic Advertising on Meat Demand." Amer. J. Agr. Econ. 77(November 1995):969-79.

Buse, R.C. "Total Elasticities-A Predictive Device." J. Farm Econ. 40(November 1958): 881-91.

Coulibaly, N. and B.W. Brorsen. "Explaining the Differences between Two Previous Meat Generic Advertising Studies.” Agribusiness 15(Autumn 1999):501-15.

De Boer, A.J. "Rural Product Promotion: Economic Aspects of Promotability, Organization and Public Assistance." Rev. Mktg. Agr. Econ. 45(December 1977):121-45.

Dorfman, R., and P.O. Steiner. "Optimal Advertising and Optimal Quality." Amer. Econ. Rev. 44(December 1954):826-36.

Forker, O.D., and R.W. Ward. Commodity Advertising: The Economics and Measurement of Generic Programs. New York: Lexington Books, 1993. 
$\rightarrow$ Hoos, S. "The Advertising and Promotion of Farm Products: Some Theoretical Issues." J. Farm Econ. 41(May 1959):349-63.

Kinnucan, H.W. "A Note on Measuring Returns to Generic Advertising in Interrelated Markets.' $\rightarrow$ J. Agr. Econ. 47(May 1996):261-67.

_- "Middlemen Behaviour and Generic Advertising Rents in Competitive Interrelated Industries." Austral. J. Agr. Resour. Econ. 41(June 1997):191-207.

$\rightarrow$ Kinnucan, H.W., and Y. Miao. "Distributiona $\rightarrow$ Impacts of Generic Advertising on Related Commodity Markets." Amer. J. Agr. Econ. 82(August 2000):672-78.

$\rightarrow$ Kinnucan, H.W., H. Xiao, C.-J. Hsia, and J.D. Jackson. "Effects of Health Information and Generic Advertising on U.S. Meat Demand." Amer. J. Agr. Econ. 79(February 1997):13-23.

Lee, H., J.M. Alston, H.F. Carman, and W. Sutton. Mandated Marketing Programs for California Commodities. Giannini Foundation Information Series No. 96-1. Oakland CA: Giannini Foundation of Agricultural Economics, University of California, 1996.

$\rightarrow$ Nerlove, M., and F.V. Waugh. "Advertising without Supply Control: Some Implications of a Study of the Advertising of Oranges." J. Farm Econ $\rightarrow$ 43(November 1961):813-37.

Parish, R.M. "Possibilities for Promoting Farm Products." Austral. J. Agr. Econ. 7(June 1963): 27-34.
Piggott, N.E. "The Benefits and Costs of Generic Advertising of Agricultural Commodities." PhD dissertation, University of California, Davis, 1997.

Piggott, N.E., J.A. Chalfant, J.M. Alston, and G.R. Griffith. "Demand Response to Advertising in the Australian Meat Industry." Amer. J. Agr. Econ. 78(May 1996):268-79.

Piggott, R.R. "Some Old Truths Revisited." Austral. J. Agr. Econ. 36(August 1992):117-40.

Piggott, R.R., N.E. Piggott, and V.E. Wright. "Approximating Farm-Level Returns to Incremental Advertising Expenditure: Methods and an Application to the Australian Meat Industry." Amer. J. Agr. Econ. 77(August 1995): 497-511.

Vande Kamp, P.R., and H.M. Kaiser. "Commodity Promotion Programs in the United States." Res. Bull. 99-01, National Institute for Commodity Promotion Research and Evaluation, Department of Agricultural, Resource, and Managerial Economics, Cornell University, 1999.

Ward, R.W., and C. Lambert. "Generic Promotion of Beef: Measuring the Impact of the U.S. Beef Checkoff." J. Agr. Econ. 44(September 1993):456-65.

Wohlgenant, M.K. "Distribution of Gains from Research and Promotion in Multi-stage Production Systems: The Case of the U.S. Beef and Pork Industries." Amer. J. Agr. Econ. 75(August 1993):642-51. 